\title{
AVALIAÇÃO DA FREQUÊNCIA DE Leishmania sp. ISOLADA EM PUNÇÃO ASPIRATIVA POR AGULHA FINA EM CÃES, ANALISADAS NO LABORATÓRIO DE DOENÇAS PARASITÁRIAS DA FACULDADE DE MEDICINA VETERINÁRIA E ZOOTECNIA - UFMS, ENTRE AGOSTO DE 2017 A SETEMBRO DE 2020.
}

\author{
(Evaluation of the frequency of Leishmania sp. isolated in aspirative puncture by fine needle in dogs)
}

Yasmin Garcia Marangoni, Carolina Isabela Mucellini, Érica Verneque Martinez, Jéssica Fernanda Gomes da Silva, Fernando de Almeida Borges

Universidade Federal do Mato Grosso do Sul, Brasil.

*Correspondência: yasming.m@hotmail.com

RESUMO: A leishmaniose visceral, na sua forma zoonótica, é causada pelo protozoário Leishmania (Leishmania) infantum chagasi e transmitida pela picada do inseto vetor, dípteros da família Psychodidae, subfamília Phlebotominae, e representa 20\% do registro de casos da leishmaniose visceral humana mundial. Nos países onde é zoonótica, como o Brasil, os cães são considerados os principais reservatórios da doença urbana. Os sinais clínicos da leishmaniose visceral canina (LVC) compreendem principalmente perda de peso, linfadenomegalia, hepatomegalia, esplenomegalia, onicogrifose e apatia, entretanto, até $80 \%$ dos cães que vivem em áreas endêmicas podem ter contato com a doença e não apresentar sintomatologia. Os métodos parasitológicos são exames considerados seguros para o diagnóstico da infecção por Leishmania spp., em razão da observação de formas amastigotas do protozoário diretamente nos tecidos do animal (TEIXEIRA et al., 2010) e a punção aspirativa por agulha fina (PAAF) dos linfonodos tem sido o exame proposto para o diagnóstico (BRASIL, 2006). O objetivo do trabalho foi avaliar a frequência de Leishmania spp. isoladas em PAAF em cães, analisadas no Laboratório de Doenças Parasitárias da Faculdade de Medicina Veterinária e Zootecnia - Universidade Federal de Mato Grosso do Sul entre agosto de 2017 e setembro de 2020. As amostras foram recebidas em lâminas de microscopia após

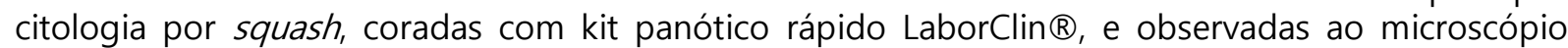
óptico no aumento de 100x em óleo de imersão. Das 539 amostras enviadas para diagnóstico, $28,20 \%$ (152/539) demonstraram formas amastigostas de Leishmania spp., enquanto 12,06\% (65/539) apresentaram material insuficiente para leitura - presença de gordura ou sangue - e $59,74 \%$ (322/539) demonstraram resultados negativos. No que diz respeito à prevenção, o contato entre o vetor infectado e o cão deve ser evitado e medidas recomendadas aos cães soronegativos ou em tratamento envolvem uso de colar impregnado com deltametrina $4 \%$, limpeza do ambiente voltada principalmente para matéria orgânica, uso de telas em canis individuais ou coletivos, exame sorológico prévio antes da doação, controle da população errante, uso de plantas que repelem insetos, bem como evitar passeios noturnos, pois é o horário de maior atividade dos flebotomíneos. Além disso, a vacinação pode ser uma estratégia recomendada, uma vez que não há tratamento que garanta a cura total da doença no cão. Em relação ao diagnóstico para a presença de amastigotas de Leishmania spp., o método de PAAF apresenta melhor sensibilidade, rápida execução e custo-benefício, entretanto, exige prática profissional tanto para a coleta do material quanto para a leitura da lâmina.

Palavras-chave: diagnóstico parasitológico; leishmaniose; PAAF

\section{Referências}

BRASIL. Ministério da Saúde. Secretaria de Vigilância em Saúde. Departamento de Vigilância Epidemiológica. Manual de vigilância e controle de leishmaniose visceral. Brasília: Ministério da Saúde, p.9, 12, 122, 2006.

TEIXEIRA, L. V.; LOPES, T.A.; MARTINS, D.B.; FRANÇA, R.T.; FIGHERA R. A. Punção aspirativa por agulha fina como método de coleta de material para a histopatologia no osteossarcoma canino. Pesquisa Veterinária Brasileira, Rio de Janeiro, v.30, n.2, 2010. 